\title{
Location of agate geodes in Permian deposits of Simota gully using the GPR
}

\author{
Michał Mierczak ${ }^{1}$ - Jerzy Karczewski ${ }^{1}$ (1)
}

Received: 16 September 2020 / Accepted: 7 January 2021 / Published online: 19 January 2021

(c) The Author(s) 2021

\begin{abstract}
The article describes the establishment of the location of agate geodes using the GPR method in the area of the Simota gully (Lesser Poland Voivodeship). Agates (a multicolored variety of gemstone of chalcedony group) have multifaceted values that informed their study. Traditional methods of geode location are less reliable, hence the attempt to use the GPR method. Measurements were taken at two study test sites with subsurface geology of weathered melaphyre and pyroclastic deposits using a GPR system (ProEx). A high-frequency antenna $(1.6 \mathrm{GHz})$ was used along with the pre-established profiles of lengths of 6-m and 10-cm intervals. Furthermore, simple soil tests using the soil sampler tool were made prior to the GPR measurement. The GPR results show significant high attenuation of the electromagnetic energy interpreted to be due to clay components of the regolith. Advanced signal processing procedures (such as the attribute of the signal) were used on the data for better enhancement that aided interpretation. Other anomalies depicted on the radargrams were thought to be the presence of roots, pieces of melaphyres-targeted agates. Furtherance to ascertain the reflection coefficients as recorded on the GPR data, in situ samples (root pieces, melaphyres, agates) taken were tested in the laboratory for electric permittivity property. Based on the interpretation results, several agate geodes were dug out from the ground.
\end{abstract}

Keywords Agate geodes · Melaphyres · Ground-penetrating radar · High-frequency measurements $\cdot$ Electric permittivity

\section{Introduction}

Deposits of gemstones, semi-precious stones and other valuable minerals (e.g., gold, diamonds) occur in various forms and geological conditions. Some are located in massive solid rocks, while others are concentrated in residual alluvial sedimentary layers. Some are large deposits covering hundreds of meters, while others are found on a small scale of the size of decimeters. In the past, their exploration was carried out using relatively simple and even primitive methods and

Communicated by Michal Malinowski (CO-EDITOR-INCHIEF)/Bogdan Mihai NICULESCU, Assoc. Prof. Dr. (Guest Editor).

Jerzy Karczewski

karcz@agh.edu.pl

Michał Mierczak

mierczak.michal@gmail.com

1 Faculty of Geology, Geophysics and Environmental Protection, AGH University of Science and Technology, 30-059 Kraków, Poland techniques. The deposits were mined manually via drilling of shot holes and the use of explosive (Cook 1997).

Starting from the 1980s, noninvasive geophysical methods were used to explore deposits of the same origin and mode of emplacement such diamonds and gold-bearing deposits. This type of deposit can be detected effectively by magnetometry and electrical methods (Cook 1997; Francke 2012), seismic method (Hammer et al. 2004), gravimetry, radiometric surveys (Irvine and Smith 1990; Smith 2002).

The mentioned above geophysical methods are characterized by relatively low resolution. With their help, it is possible to detect specific geological structures such as faults and folds, boundaries between different geological formations, but no specific identification of a mineral type. However, a versatile noninvasive geophysical method known as ground-penetrating method (GPR) may also be used for such exploration. GPR is a very high-resolution geophysical exploration method. The ground-penetrating radar method belongs to the group of radio-wave methods using changes to signals to which the electromagnetic wave transmitted deep into the geological medium is subjected. The electromagnetic wave emitted by the GPR is transmitted via antenna 
and propagates through the rock mass then reflected at the border of contrasting electrical permittivity. Then, the wave is recorded by the receiving antenna. The received wave image reflects the geological structures of the medium. The GPR equipment consists of two antennae: transmitting and receiving. The transmitting antenna emits a short electromagnetic pulse into the rock mass. Such GPR systems working on that principle are referred to as radars with impulse amplitude modulation. The frequency of antennas varies between $10 \mathrm{MHz}$ and $4 \mathrm{GHz}$. It allows us to precisely investigate the structure of the near-surface zone; depending on the frequency of the antennas which has a range up to several dozen meters. A comprehensive introduction to the GPR method can be found, among others in the works (Daniels 2004; Jol 2008; Karczewski et al. 2011; Tomecka and Marcak 2015).

Manu et al. (2013) have studied the Subenso-north gold deposit (Ghana) using the GPR method. Aranha et al. (2018), Horn et al. (2018) used georadar to study pegmatite veins (which may contain tourmalines) in Santa Rosa Pegmatite Field in Minas Gerais (Brazil). Patterson and Cook (2002) used GPR together with high-frequency $1000 \mathrm{MHz}$ antennas to search for tourmalines in Himalaya Pegmatite Mine (California, USA).

This article describes an attempt to localize agate geodes occurrences using the GPR method in the region of the Simota gully, Poland. Agates, as a semi-precious stone, are a frequent target for mineral prospectors. They have been known almost since ancient times. The first specimens were found on cultivated fields, especially during agricultural works and snowless beginning of winter. Therefore, continuous assessment and evaluation of its traces of occurrences cannot be overemphasized.

Agates have high scientific and marketable value. It is a multicolored, ribbonized variety of chalcedony. Mineralogically, they are formed in stable conditions as a result of silica crystallization from hydrothermal solutions. They are built of many concentric, multicolored layers. The color variation is caused by the presence of various minerals (e.g., hematite, goethite, celadonite, manganese oxides). Geological settings and mode of emplacement suggest that they are usually found in the cavities of alkaline flooded rocks, mainly melaphyres. They are usually formed in the form of geodesy, sometimes among sedimentary rocks. Agate blocks have a spherical, ellipsoidal or almond-like form, they can also be irregular or take vein forms. Very often they form druses, i.e., voids inside the stone lined with crystals. Agate deposits occur mainly in South America (Brazil, Uruguay), moreover, in Mexico, India, the USA, Mongolia, Madagascar, Morocco, Iran and many other places (Dumańska-Słowik et al. 2013; Salimi and Renfro 2019; Natkaniec-Nowak et al 2020). In Poland, the richest speeches of agates are located in Lower Silesia (Nowy Kościół, Płuczki Górne). In Lesser
Poland area, agates appear near Krzeszowice (Rudno and Regulice) (Mierczak 2019).

Until now, collectors have been increasing the effectiveness of exploration through a combination of geological knowledge and field experience, and the extraction works through various mining techniques have been carried out mainly using simple tools such as spades, hammers and pickaxes. Of course, everything depended on the characteristics of the deposit.

The effectiveness of the traditional methods localization of agates is unsatisfactory, hence the attempt to apply another alternative method. GPR is a non-destructive, very fast and efficient method of detection. This article presents the results of the study which aim was to localize agate geodes occurrences in the region of the Simota gully, Poland with using the GPR method. Additionally, the description of the attempt to determine the electrical permittivity, which is one of the most important parameters of a geological medium used in GPR method, in the laboratory conditions, for various samples taken from the measurement site, was provided.

\section{Location and geological setting of the study area}

Simota gully is located west of Regulice village (Lesser Poland Voivodeship). From the geological and tectonic point of view, it is situated on the edge of the Nieporaz-Brodło sinkhole, within the Tenczyński Hump (Fig. 1).

In the vicinity of Regulice, at the turn of the Carboniferous and Permian regions, melaphyres were formed in three lava cycles, which are overlaid with pyroclastic xenoliths. The thickness of its pieces as found in the region sometimes

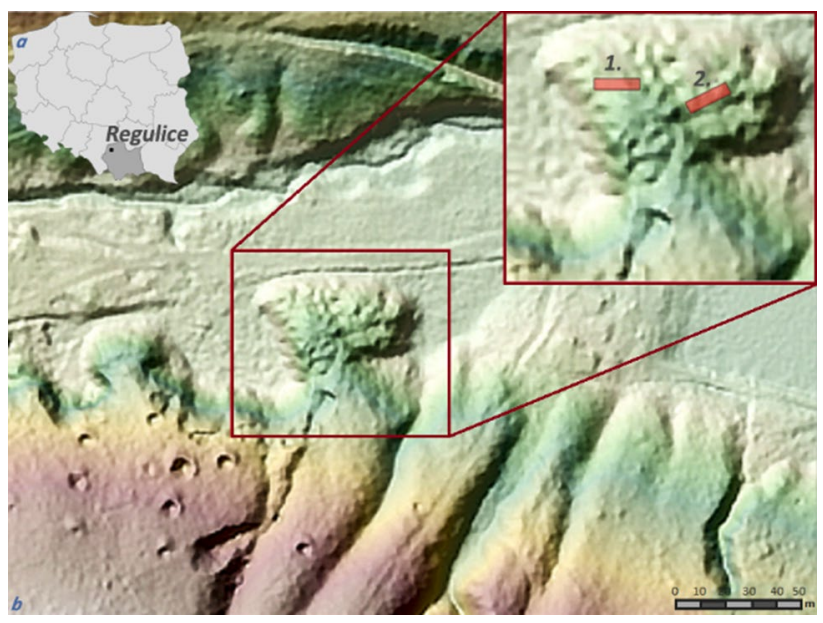

Fig. 1 Location of the measurement area. a On the map of Poland, b on the lidar image 
reaches $50 \mathrm{~m}$. All series of paleobasaltes in the region were emplaced in a similar way which results in massive basalts in the floor that transformed into a melaphyre with numerous gas bubbles in the ceiling, sometimes reaching a spongy texture. Voids are filled with various secondary minerals such as calcite, iddingsite, zooliths, quartz, amethyst, jasper, heliotrope and agates. Agate secretions sometimes contain native copper (Krawczyński 1995). The whole composition is supported by melaphyre breccia (Birkenmajer 1964).

Pyroclastic compositions are fine ash tuff with meliorated volcanic bombs of fluidized structure, size up to $40 \mathrm{~cm}$. The sludge is characterized by the presence of many series with fractional grain size. This indicates episodic transport in the form of local surface runoffs (Chocyk 1990). The character and color of the sedimentation indicate a continental sedimentary environment, in a climate similar to the contemporary subtropical zones. Intensive weathering that occurred in the region was thought to have taken place during the upper Permian period (Szulc and Ćwiżewicz 1989). Volcanoes occur in the vicinity of the lines surrounding the collapse of Nieporaz-Brodła. They lie mainly on the Kwaczalska Arkose, and in some places on the Myslichowicki conglomerate.

The sediments of the lower Triassic are represented as cluster rocks of terrestrial origin. These are mainly sandstones and arkose sandstones (Siedlecki 1951). In the upper part of the Lower Triassic, transgression began with the deposition of marls, limestone and dolomites. Meanwhile, during the middle Triassic period, shelly limestone sedimentation occurred. These formations were overlain by the Mesozoic rocks but are currently not present because of deposition that occurred in the Paleogene.

The period of the Hiatus lasts from shell limestone deposition to Paleogene, during which weathered materials covers were formed as a result of erosion, and carbonates were subjected to karst processes. This time also marks the beginnings of the creation of the present river network (Jaworski 1993).

The Miocene period heralded the deposition of marine clay and limestone sediments; however, they were eroded in Pliocene and Pleistocene. They are not present in the studied area. In Pleistocene, as a result of the rising of the erosion base, narrow river channels of Tenczyński's horst were filled in and flat-bottomed valleys were created in their place. As a result of eolian transport, the whole area was covered with loesses, which have survived until now in the form of loesses of the upland. Holocene sediments are large cluster rocks of fluvial origin. There was also an erosion of loess covers and exhumation of karst funnels.

The Regulice-Simota melaphyres are most probably a continuation of the Regulice Czarna Góra quarry, mine where a volcanic cone was most probably located. Melaphyres are found all over the studied area. Their presence north of Simota gully is proved by the continuity of the outcrops in the left-bank tributary of Simota gully, but they were not included in the Detailed Geological Map of Poland. The fact that on the left side of the gully the paleobazalts are covered with a thick layer of limestone is evidenced by the presence of karst craters, exhumed during the Holocene. The type of Paleogene denudation depends on the bedrock, and it reaches the greatest thickness in the plateaus. The piece of interest to us is the intact melaphyric regolith in a place not covered with a layer of loess. The presence of an uncovered layer of tuffites-which are intermediate layers between the melaphyres-may indicate that it was eroded in the upper Permian, or another lava stream did not reach the study area. In the pyroclastic formations, they most probably came from the fluvial transport and come from the older rocks-the Myslowice conglomerate and the Kwaczalska arkose. The occurrence of deposit redeposition is demonstrated, among others, by the presence of different monolith residues with a similar degree of weathering in one place. The interpreted geological cross section is presented in Fig. 2.

Essentially, the research was carried out on a mixture of partially weathered melaphyres and pyroclastic compositions.

Perhaps particles of Mesozoic carbonates were also present there, but they might have been dissolved. Pieces of similar characteristic deposits are found in the vicinity of Alwernia. In the regolith, there is a concentration of agates, because of their greater resistance to weathering than the surrounding host rocks, as well as transportation of the products of weathering.

\section{Method of study}

As already mentioned, the GPR method was used to search for agates. The electromagnetic wave emitted by the GPR propagating in the rock mass is reflected, refracted and suppressed. The most important phenomenon, from the point of view of the GPR method, is the reflection of the wave on the border of two propagating media of contrasting electrical permittivity.

The amplitude of the reflected impulse is proportional to the difference in the electrical permittivity of both media. These relationships are described by formulas:

$$
r=\frac{\sqrt{\varepsilon_{1}}-\sqrt{\varepsilon_{2}}}{\sqrt{\varepsilon_{1}}+\sqrt{\varepsilon_{2}}} ; \quad A_{r}=r \cdot A_{i},
$$

where $r$ reflection coefficient, $\varepsilon_{1}, \varepsilon_{2}$ relative permittivities of layers, $A_{r}$ amplitude of the reflected wave, $A_{i}$ amplitude of the incident wave.

In the actual geological medium, the electromagnetic wave is strongly attenuated. The depth range of the GPR 
Fig. 2 Schematical geological cross section of the Simota gully with the measurement area marked

\section{SURVEY AREA}

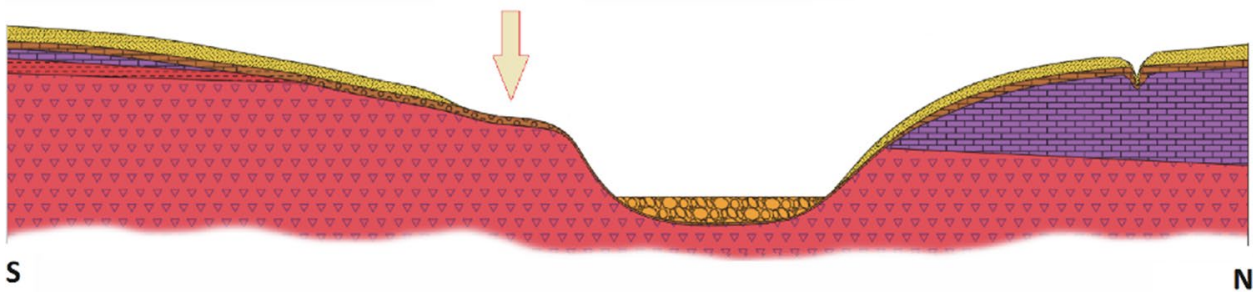

Legend:

\begin{tabular}{|c|c|}
\hline Lithology: & Epoch: \\
\hline 파재정 alluvium & Pleistocene - Holocene \\
\hline loess & Pleistocene \\
\hline 도모 limestone regolith & \\
\hline 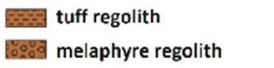 & Paleogene \\
\hline 臣 limestone & Early Triasic - Middle Triasic \\
\hline $\begin{array}{l}\text { tuff and volcanic bombs } \\
\text { melaphyre }\end{array}$ & Cisural (Permian) \\
\hline
\end{tabular}

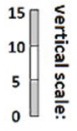

horizontal scale:

\begin{tabular}{llllll}
0 & 5 & 10 & $15 \quad 20 \quad 25$ \\
\hline
\end{tabular}
Table 1 The conductivity and attenuation coefficient of some materials (based on Sharma 1997; Daniels 2004)

\begin{tabular}{lll}
\hline Material & $\sigma[\mathrm{S} / \mathrm{m}]$ & $\alpha[\mathrm{dB} / \mathrm{m}]$ \\
\hline $\begin{array}{l}\text { Humus } \\
\text { level with }\end{array}$ & 0.015 & 5 \\
roots & & \\
Loess & 0.1 & 50 \\
Tuffite & 0.1 & 40 \\
Melaphyre & 0.05 & 25 \\
Sand (dry) & 0.001 & 0.8 \\
\hline
\end{tabular}

directly depends on the moisture contents. The attenuation increases with the frequency of the wave propagating in the medium; it also depends on the medium parameters, mainly conductivity (Daniels 2004).

In the low-lossy media, the following relationship can be used to calculate the attenuation coefficient (Sharma 1997):

$\alpha \approx 1685 \cdot \frac{\sigma}{\sqrt{\varepsilon_{r}}}\left[\frac{\mathrm{d} B}{m}\right]$,

where $\alpha$ attenuation coefficient $[\mathrm{dB} / \mathrm{m}], \sigma$ conductivity [S/m], er relative permittivity.

Table 1 shows the conductivity and attenuation coefficient of some material in the area of measurements. The comparison of the materials attenuation coefficient and dry sand is as shown in Table 1.

An additional limiting factor in the GPR method is the scattering of the wave front on numerous small objects (e.g., tree roots, animal burrows, etc.). The scattering depends on the frequency of the antenna. The higher the frequency, the greater the scattering.

The key problem when searching for agates using the GPR method is the resolution of the measurement. A distinction is made between vertical and horizontal resolution (Karczewski et al. 2011). In this case, horizontal resolution is more important - the ability to distinguish two objects lying at the same depth. The following relationship was used to calculate the horizontal resolution:

$\Delta R=\sqrt{\frac{h \cdot \lambda_{c}}{2}}$,

where $\Delta R$ horizontal resolution, $\lambda_{\mathrm{c}}$ center frequency wavelength, $h$ depth of the object.

Due to the fact that the size of the objects sought which ranges around $0.15 \mathrm{~m}( \pm 0.05 \mathrm{~m})$, high-frequency antennas were used. The choice of frequency antennas considered was between $1.6 \mathrm{GHz}$ and $800 \mathrm{MHz}$. The former is supported by higher resolution, the latter by lower attenuation. The horizontal resolution of both proposed antennas was evaluated (Fig. 3). For the purpose of calculations, the electromagnetic wave velocity in the geological medium $\mathrm{v}=0.08 \mathrm{~m} / \mathrm{ns}$ (velocity for clay formations of moderate humidity according to Jol 2008) was assumed.

The graph shows a red dashed line for the resolution range that corresponds to the size of the agates sought. Most typical agate specimens fall within this range. An $800 \mathrm{MHz}$ antenna allows the detection of objects with a diameter of about $15 \mathrm{~cm}$ only to a depth of about $45 \mathrm{~cm}$ (Fig. 4), and this does not allow reaching below the humus level. Therefore, the $1.6 \mathrm{GHz}$ High-Frequency antenna was chosen for the measurements, which allows to record objects of about $15 \mathrm{~cm}$ in size at a depth of almost one meter. The limitation here may be the attenuation of electromagnetic waves in the geological medium.

It has been assumed that the geodes in the radar image will create characteristic hyperbolic anomalies. Migration 


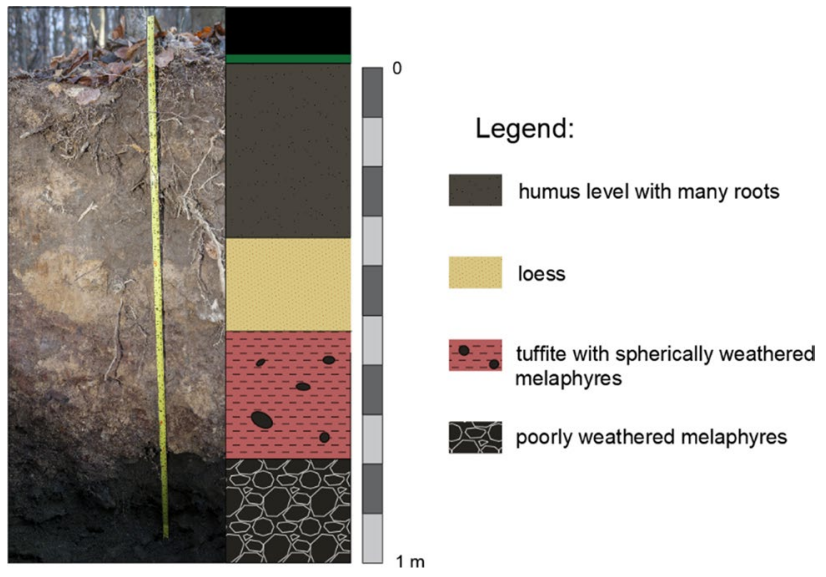

Fig. 3 The geological column of a point at the measurement site

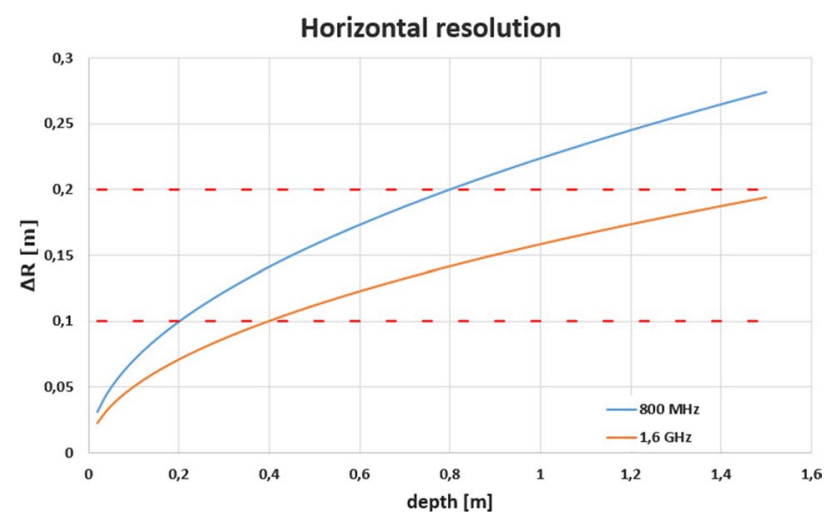

Fig. 4 Dependency of the horizontal resolution on the depth for antennas of different frequencies

was used to separate such zones and then the envelope of the radar signal was calculated (Patterson and Cook 2000). The signal envelope is determined using the Hilbert transformation. Hilbert's simple and reverse transformation is determined by the following relationships (Szabatin 2000):

$\hat{x}(t)=\frac{1}{\pi} \int_{-\infty}^{\infty} \frac{x(\tau)}{t-\tau} \mathrm{d} \tau$

$x(t)=-\frac{1}{\pi} \int_{-\infty}^{\infty} \frac{x \hat{(\tau)}}{t-\tau} \mathrm{d} t$,

where $\{\hat{x}\}$-Hilbert transform of $\{x\}$.

An analytical signal of the $\mathrm{x}(\mathrm{t})$ signal is called a combined signal with(t) given the following expression:

$z(t)=x(t)+i \cdot \hat{x}(t)$

The real part of the analytical signal is the primary signal and the imaginary part is its Hilbert transform. The instantaneous amplitude or envelope $\mathrm{X}(\mathrm{t})$ of the signal $\mathrm{x}(\mathrm{t})$ is called the module of its analytical signal:

$X(t)=|z(t)|=\sqrt{x^{2}(t)+\hat{x}^{2}(t)}$.

Analysis of the instantaneous amplitude (envelope) in relation to GPR measurements gives satisfying results (Karczewski 2011). It allows for easier extraction of reflections of the highest amplitudes and energies. The variability of the envelope is much smaller than the variability of the signal itself. In practice, it is much easier to locate the part of the signal with the highest amplitude analyzing its envelope.

\section{Field measurements}

The measurements were planned and performed at two measurement areas marked as FIELD1 and FIELD2 (Fig. 1b). The ProEx System georadar from the Swedish company MALÅ GeoScience was used (Fig. 5). It is a twochannel GPR system manufactured since 2008. All antennas manufactured by the company, with frequencies from $25 \mathrm{MHz}$ to $2.3 \mathrm{GHz}$, can be connected to it. For measurements, as already mentioned, an antenna of $1.6 \mathrm{GHz}$ has been chosen. The antenna is installed on a special measuring cart equipped with a distance measuring wheel (Fig. 5b).

In the beginning, using the soil sampler tool, the areas where the melaphyre regolith was thickest and also devoid of loess cover were selected, two places with the least

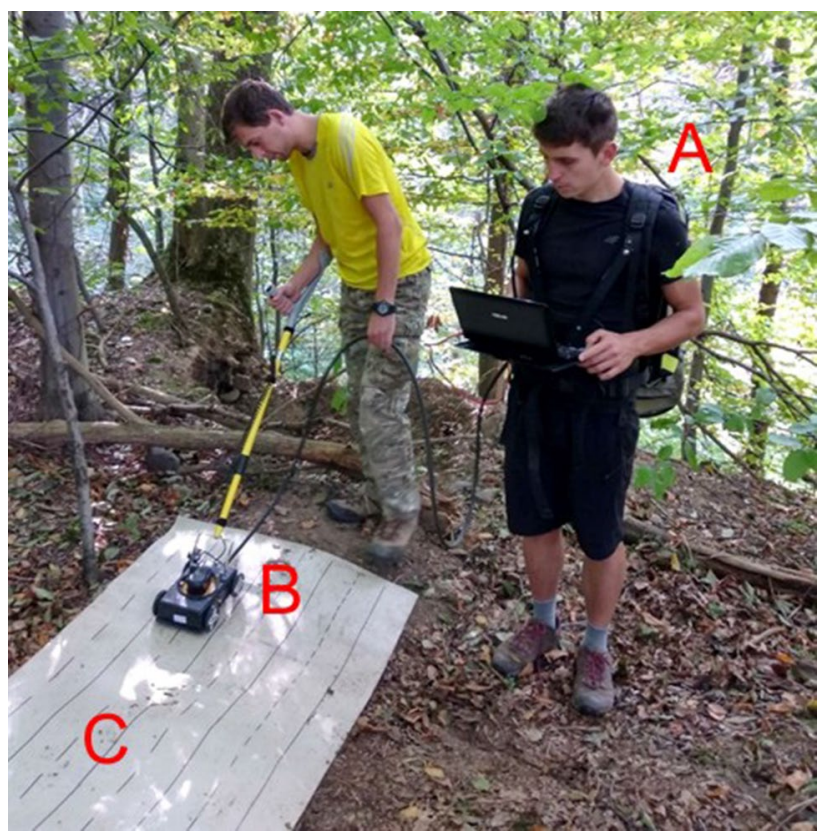

Fig. 5 Field measurements setup. a ProEx System in the backpack; b $\mathrm{HF}$ antenna, $\mathbf{c}$ PCV measuring mat (photograph by J. Karczewski) 
possible varied terrain morphology were selected. In each of the areas, a grid of 8 parallel profiles that are $10 \mathrm{~cm}$ apart was designed. The length of each profile is $6 \mathrm{~m}$. In order to increase the effectiveness of the measurements and improve the contact of the measuring wheel with the ground, the measurements were made on a special measuring mat made by the authors (Fig. 5c).

On the FIELD1, the thickness of the regoliths is about $1 \mathrm{~m}$, so the time window was set to $20 \mathrm{~ns}$, and on FIELD2 the registration time was extended to $25 \mathrm{~ns}$ (due to the higher thickness of melaphyric regolith and the humidification level). The fieldwork was carried out in conditions of low ground moisture contents, a period when there was no precipitation for about 2 weeks earlier (thus, the wave attenuation in the center is then significantly lower).

Table 2 shows the basic measurement parameters selected in the Ground Vision data acquisition software.

A small distance interval (distance between traces, A-Scans) was selected due to its importance when trying to locate small objects. The 16 signal stacking was used, allowing for a significant $\mathrm{S} / \mathrm{N}$ ratio increase.

Table 2 The basic GPR system input measurement parameters

\begin{tabular}{lc}
\hline Parameter & Value \\
\hline Distance interval & $1 \mathrm{~cm}$ \\
Time window & $26 \mathrm{~ns}$-FIELD1; \\
& $30 \mathrm{~ns}-$ \\
Stacking & FIELD2 \\
Number of samples & 16 \\
\hline
\end{tabular}

\section{Results and discussion}

The results of the GPR measurements needed to be processed in order to improve the correlation of useful reflections and improve the $\mathrm{S} / \mathrm{N}$ ratio. The procedures commonly used are time-varying signal amplification, standard filtration, migration and others. Modeling and simulation of real geological conditions that respond to the electromagnetic field may also enhance GPR interpretations and deductions (Akinsunmade et al. 2019). All data were processed with the ReflexW program of the German company Sandmeier.

The primary purpose of the measurements was to delineate agates or other silica secretions. Like all small-sized anomalies, they should be marked as diffraction hyperboles.

On FIELD1, two interesting objects were identified on radargrams (plot of signal amplitude against travel time of the field data). The first one was registered on profile no. 4 , at a distance of $5.1 \mathrm{~m}$ and $10 \mathrm{~cm}$ deep (Fig. 6).

The zone marked with a green ellipse is a place where numerous roots of the tree growing in the vicinity of FIELD1 can be found. Agate located on the profile is shown in Fig. 7.

Another object identified by the GPR method results is a large (about $15 \mathrm{~cm}$ ) agate with a poorly ordered structure and low collector's value. It was located on the profile no. 7 (140 cm of the profile, at the depth of $15 \mathrm{~cm}-$ Fig. 8); it is marked with a red circle. It is a quartz brush with rutile insides; on the bottom side, it is stained with goethite. It grew on agate covered with sagenites (Fig. 9).

The color purple was distinguished by hyperboles coming mainly from weathered melaphyres and also from roots.

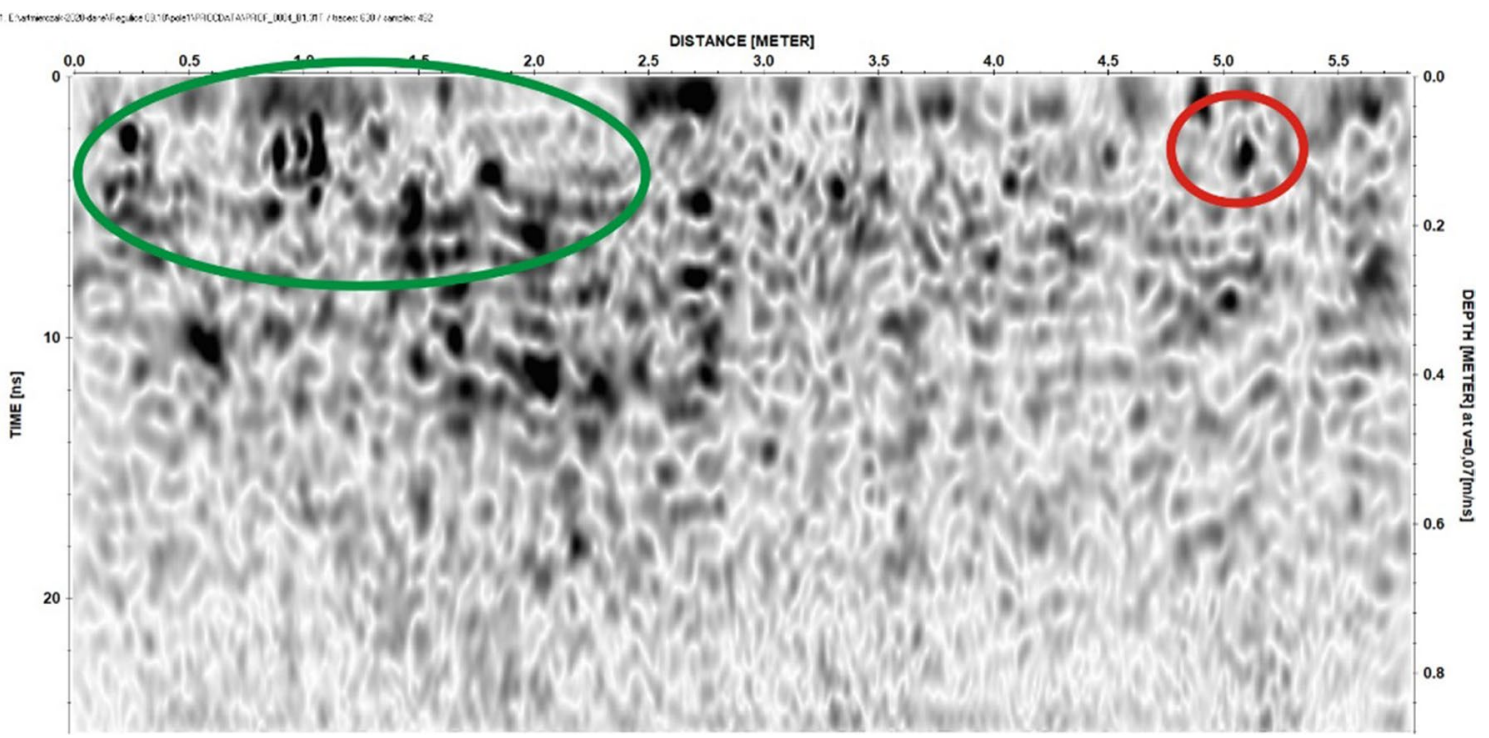

Fig. 6 Radargram of a profile 4 in the FIELD1 with green ellipse indicating tree roots and red circle indicating an agate 


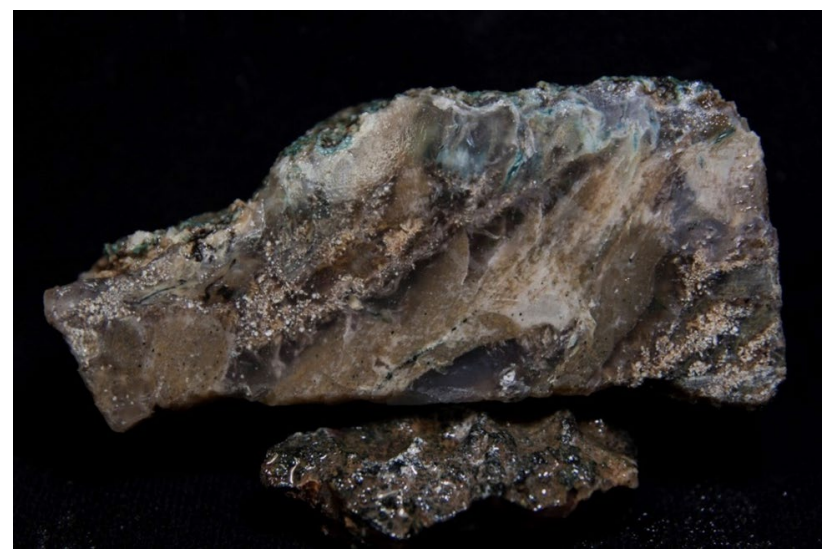

Fig. 7 The polished agate located on the profile 4; FIELD1 (photograph by M. Mierczak)

On FIELD2, the GPR was used to locate another object suspected to be one agate on profile 2 (Fig. 10). It is multicolored agate of ribbon structure (Fig. 11).

As in previous radargrams, in the place marked in green we observe numerous anomalies caused by the presence of tree roots in the vicinity of profiles. Delineation of the objects located at far depth is significantly difficult.

It should be added that in case FIELD2, the envelope of georadar signal was not calculated during data processing. Thanks to that, on most of the profiles on FIELD2 we were able to observe the reflection on time about $25 \mathrm{~ns}$ (depth about $1 \mathrm{~m}$ ). It was marked with a yellow arrow in Fig. 9. It most probably comes from a layer of iron oxides, located at a depth of about $1 \mathrm{~m}$ (Fig. 12). Such precipitations often appear in the illuvial horizon.

The regolith leached zone also contains much more clayey substances, which increases its conductivity and electric permittivity. This results in a significant increase in damping and a reduction in the depth range and reflection from objects with high contrast electrical properties.

\section{Laboratory measurements}

In order to know the actual reflection coefficients at the borders between different objects in the study area, the samples obtained in the field were tested in order to estimate the electrical permittivity value epsilons. The research was carried out in the petrophysical laboratory of the Faculty of Geology, Geophysics and Environmental Protection of AGH UST.

The relationship between capacitance of the capacitor and electrical permittivity of the material between plates was used here (Plewa and Plewa 1992). The measurement consisted of measuring the capacitance of a capacitor with a sample of material inserted between its plates and the capacitance of a vacuum capacitor with an unchanged distance between the plates. The tests were performed at a current frequency of $100 \mathrm{~Hz}$. The results are shown in Table 3.

There were 3 types of melaphyres in the study area, solid black, cherry, which were more weathered, and spongy melaphyres most affected by weathering. This is well reflected in their calculated electrical permittivity values. As you can see (Table 2), tree roots and agates have similar values of electric permittivity, which makes it difficult to distinguish

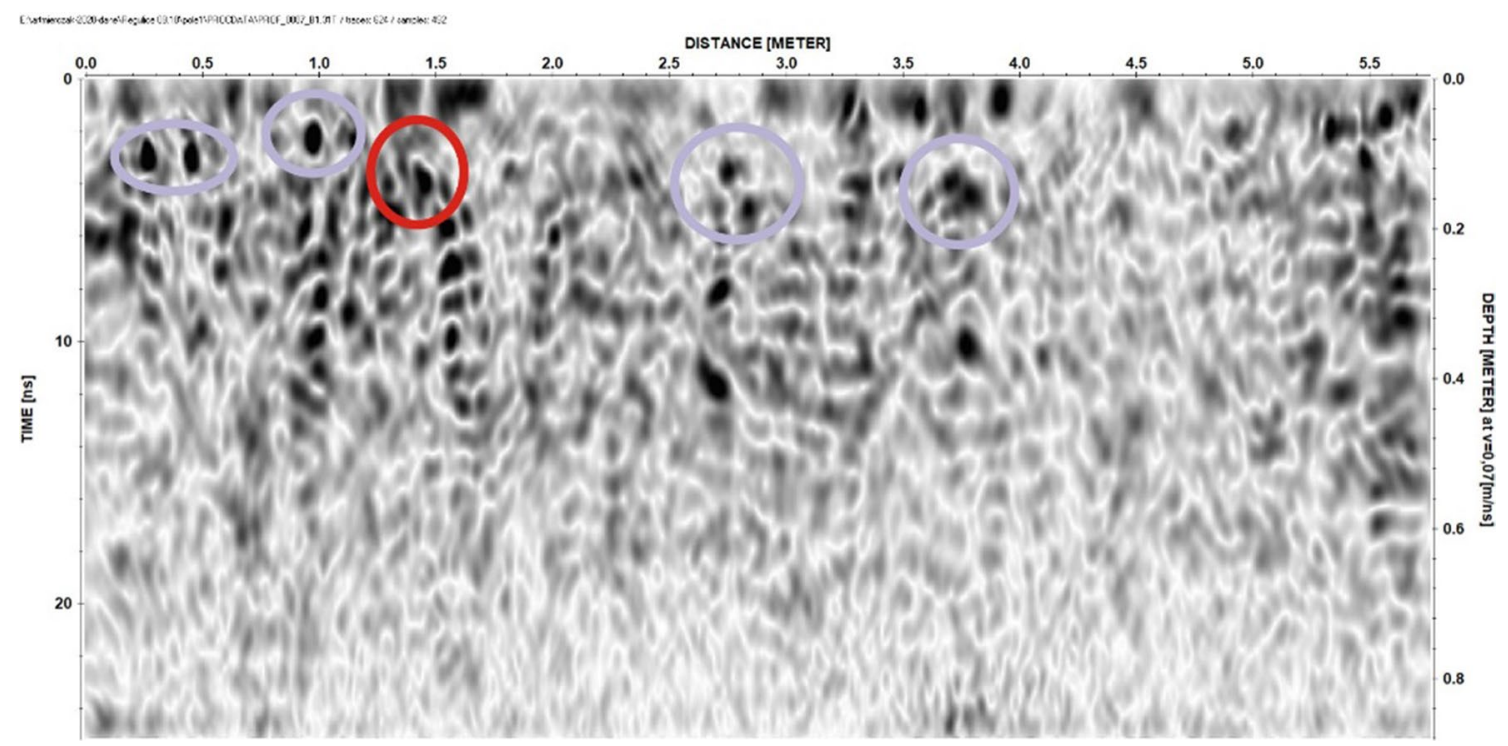

Fig. 8 Radargram of the profile 7 in the FIELD1 with purple circles indicating weathered melaphyres and tree roots and red circle indicating an agate 


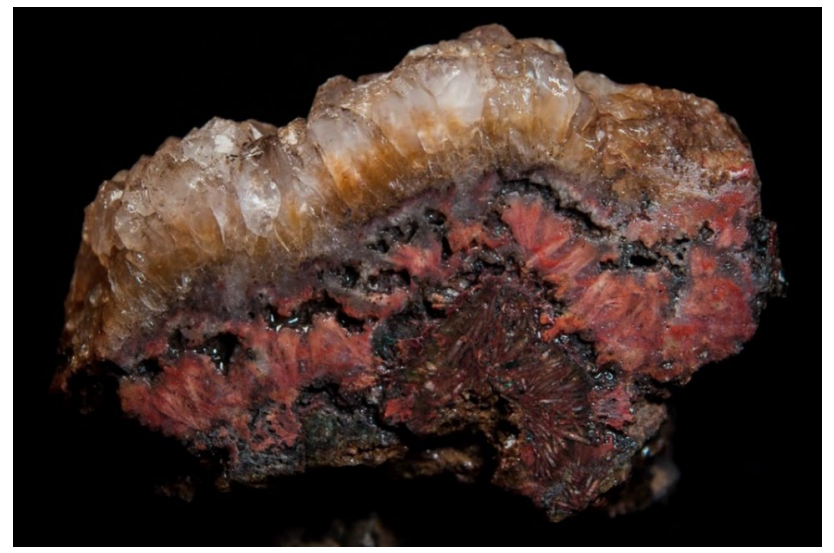

Fig. 9 The polished agate located on the profile 7; FIELD1 (photograph by M. Mierczak)

tree roots from agates in the GPR image. An attempt was also made to determine the permeability of soil taken from the place of measurements. Unfortunately, the results of these studies were not reliable and were characterized by high variability.

\section{Conclusions}

The GPR method records reflections from objects with different electrical permittivities, such as agates, melaphyres, roots or small voids (e.g., mouse burrows). Distinguishing the sources of anomalies is very difficult in practice.

Understanding of processes involved during measurements can increased the search efficiency. The shallower the material, the more weathered it is, so it has higher

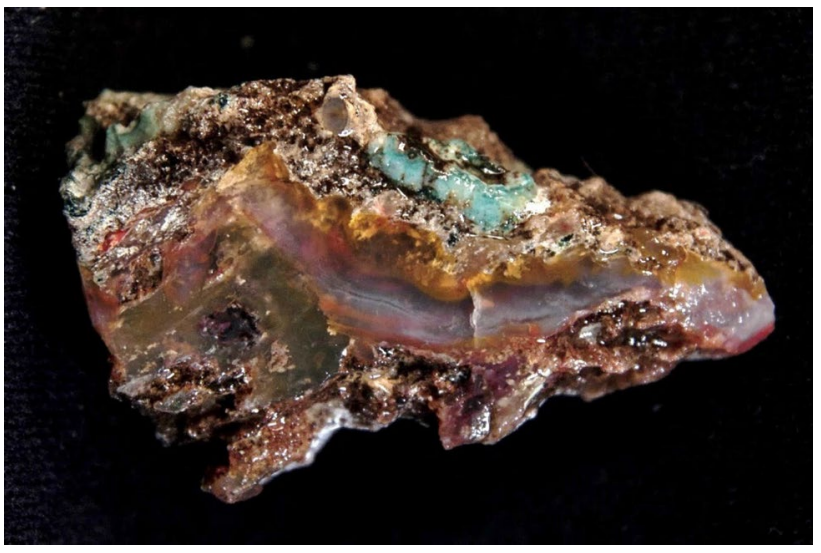

Fig. 11 The polished multicolored agate located on the profile 2; FIELD2 (photograph by M. Mierczak)

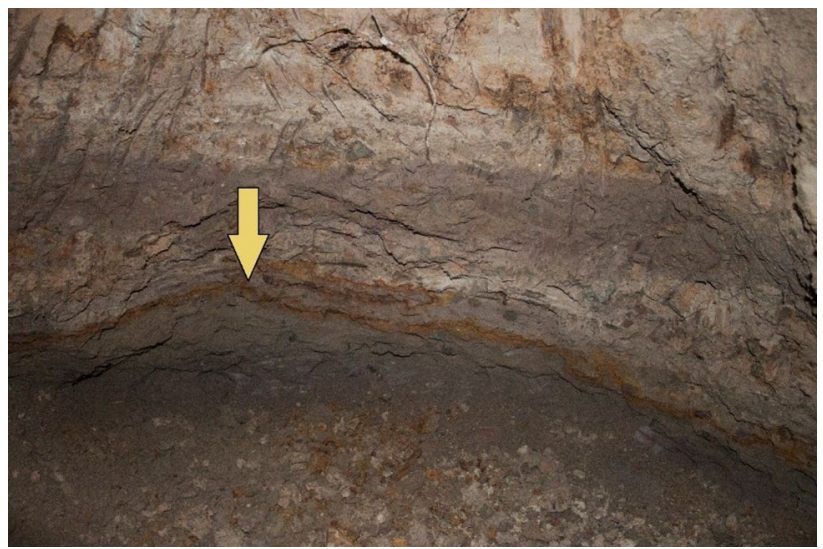

Fig. 12 Well visible layer traces of iron oxides in the FIELD2 (photograph by M. Mierczak)

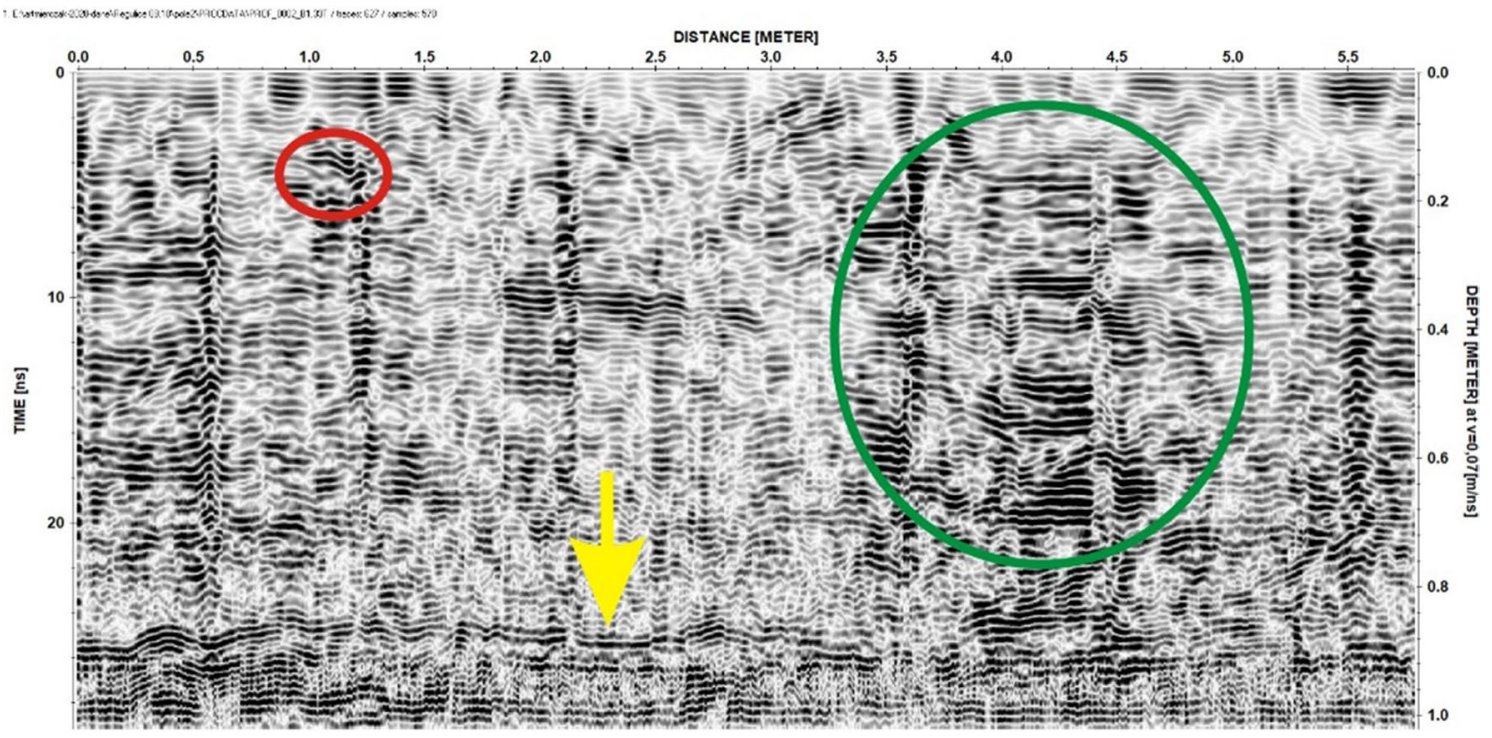

Fig. 10 Radargram of the profile 2 in the FIELD2 with green ellipse indicating tree roots and red ellipse indicating a multicolored agate 
Table 3 Laboratory estimated electrical permittivities of some materials samples taken from the survey area

\begin{tabular}{lc}
\hline Material & $\varepsilon_{\mathrm{r}}$ \\
\hline Tree root & 2.71 \\
Melaphyre & 7.00 \\
Cherry melaphyre & 10.0 \\
Spongy melaphyre & 29.0 \\
Agate & 3.80 \\
\hline
\end{tabular}

electrical permittivity (see Table 2). The grain size also decreases during weathering. Silica disintegrates slower than melaphyres, but in the surface layers the agates should be larger and less weathered than the rest of the regoliths. This makes the near-surface layer the most favorable for the search for silica secretions. Therefore, a small depth range of high-resolution antennas is not a limitation, but the advantage is the high resolution of such antennas (see Fig. 3).

The main difficulty associated with interpretation in this research is the multitude of anomalies and scattering of the wave front and the clay character of the weathered materials, which significantly increases attenuation. During measurements in forest areas, the greatest difficulty is the anomalies from numerous tree roots in the near-surface layer. The location and correct interpretation of the anomalies lying below are very difficult. Nevertheless, on both plots we managed to locate some interesting mineralogical specimens (Figs. 6, 8, 10). The objects were identified on radargrams, dug and polished. On FIELD2, we managed to identify the level of iron oxides at a depth of about $1 \mathrm{~m}$.

In summary, the combination of a comprehensive understanding of the geology of the area and the skilful use of GPR can significantly increase the efficiency of searching for agate geodes.

Acknowledgments The results are part of the statutory research AGH University of Science and Technology, Krakow, Poland, Project No. 11.11.140.645. The paper was financially supported by the research subsidy nr. 16.16.140.315 at the Faculty of Geology, Geophysics and Environmental Protection of the AGH University of Science and Technology, Krakow, Poland, 2020. We would like to extend our sincere thanks to Mateusz Moroz for help in taking measurements. We would like to thank the editor and anonymous reviewers for providing valuable and insightful feedback on the manuscript.

Open Access This article is licensed under a Creative Commons Attribution 4.0 International License, which permits use, sharing, adaptation, distribution and reproduction in any medium or format, as long as you give appropriate credit to the original author(s) and the source, provide a link to the Creative Commons licence, and indicate if changes were made. The images or other third party material in this article are included in the article's Creative Commons licence, unless indicated otherwise in a credit line to the material. If material is not included in the article's Creative Commons licence and your intended use is not permitted by statutory regulation or exceeds the permitted use, you will need to obtain permission directly from the copyright holder. To view a copy of this licence, visit http://creativecommons.org/licenses/by/4.0/.

\section{References}

Akinsunmade A, Karczewski J, Mazurkiewicz E, Tomecka-Suchoń S (2019) Finite-difference time domain (FDTD) modeling of ground penetrating radar pulse energy for locating burial sites. Acta Geophys 67(6):1945-1953

Aranha PRA, Horn AH, Joncew HC (2018) Use of GPR in pegmatite mining: example of a sheetlike body from northern Minas Gerais. Brazil Rom J Mineral Deposits 91(1-2):7-12

Birkenmajer K, Nairn AEM (1964) Palaeomagnetic Studies of Polish Rocks. Roczniki Polskiego Towarzystwa Geologicznego, XXXIV 1-2:229-231

Chocyk M (1990) Late paleozoic pyroclastic deposits from Regulice near Alwernia [in Polish]. Przegląd Geologiczny 38:390-393

Cook FA (1997) (1997) Applications of Geophysics in Gemstone Exploration. Gems \& Gemology, Spring 33(1):4-23

Daniels DJ (ed) (2004) Ground penetrating radar $-2^{\text {nd }}$ edition. The Institution of Electrical Engineers, London

Dumańska-Słowik M, Natkaniec-Nowak L, Wesełucha-Birczyńska A, Gaweł A, Lankosz M, Wróbel P (2013) Agates from Sidi Rahal, in the Atlas Mountains of Morocco: Gemological Characteristics and Proposed Origin. Gems Gemology Fall. 49(3):148-159

Francke J (2012) A review of selected ground penetrating radar applications to mineral resource evaluations. J Appl Geophys 81:29-37

Hammer PTC, Clowes RM, Ramachandran K (2004) Seismic reflection imaging of thin, kimberlite dykes and sills: exploration and deposit characterization of the Snap Lake dyke, Canada. Lithos 76:359-367

Horn AH, Aranha PRA, Joncew HC (2018) Combined mineralochemical, statistical and geophysical (GPR) data as support for the exploration of pegmatite-hosted gemstones: example from the Santa Rosa mine, MG. Brazil Rom J Mineral Deposits 91(1-2): $1-6$

Irvine RJ, Smith MJ (1990) Geophysical exploration for epithermal gold deposits. J Geochem Explor 36(1-3):375-412

Jaworski K (1993) Objaśnienia do SMGP arkusz 972 Krzeszowice, SMGP

Jol HM (ed.) (2008), Ground penetrating radar theory and applications. Elsevier

Karczewski J (2011) Application of GPR method to investigate in protected areas. Polish J Environ Stud 20(4A):115-119

Karczewski J, Ortyl Ł, Pasternak M (2011) The outline of GPR method. [in Polish]. Wydawnictwa AGH, Kraków

Krawczyński W (1995) Native copper in agates from Rudno near Krzeszowice. Mineralogia Polonica 26(1):27-33

Manu E, Preko K, Wemegah DD (2013) Application of Ground Penetrating Radar in delineating zones of Gold Mineralization at the Subenso North Concession of Newmont Ghana Gold Limited. Int J Sci Res Publ, 3(5), ISSN 2250-3153; DOI: 10.29322

Mierczak M (2019) Attempt to locate agate geodes with GPR in the area of Simota Gully (Lesser Poland Voivodeship) [in Polish]. Dissertation, AGH UST, Faculty of Geology, Geophysics and Environmental Protection

Natkaniec-Nowak L, Dumańska-Słowik M, Gaweł A, Łatkiewicz A, Kowalczyk-Szpyt J, Wolska A, Milovská S, Luptáková J, Ładoń K (2020) Fire agate from the Deer Creek deposit (Arizona, USA) - new insights into structure and mineralogy. Mineral Mag 84(2):343-354

Patterson JE, Cook FA (2000) Application of complex trace analysis for improved target identification in gem-tourmaline-bearing 
pegmatites in the Himalaya mine, San Diego County, California. Proc. SPIE 4084, Eighth International Conference on Ground Penetrating Radar, Gold Coast, Australia. https://doi.org/https ://doi.org/10.1117/12.383537

Patterson JE, Cook FA (2002) Successful Application of Ground Penetrating Radar in the Exploration of Gem Tourmaline Pegmatites of Southern California. Geophys Prospect 50(2):107-117. https ://doi.org/10.1046/j.1365-2478.2002.00312.x

Plewa M, Plewa S (1992) Petrofizyka, Wydawnictwo Geologiczne

Salimi MM (2019) Renfro N (2019) Plume Agate from Iran. Gems \& Gemology, Summer 55(2):278

Sharma PV (1997) Environmental and engineering geophysics. Cambridge University Press, UK

Siedlecki S (1951) Utwory Stefańskie i Permskie we wschodniej części Polskiego Zagłębia Węglowego. Acta Geol Pol 2(3):300-348
Smith RJ (2002) Geophysics of iron oxide copper-gold deposits. In: Porter TM (ed) Hydrothermal iron oxide copper-gold and related deposits: a global perspective, vol 2. PGC Publishing, Canada, pp 357-367

Szabatin J (2000) Podstawy teorii sygnałów. WKŁ, Warszawa

Szulc J, Ćwiżewicz M (1989) The lower permian freshwater carbonates of the Slawkow graben, Southern Poland: Sedimentary facies context and stable isotope study. Paleogeography, Paleoclimatology, Paleoecology no 70:107-120

Tomecka-Suchoń S, Marcak H (2015) Interpretation of Ground Penetrating Radar Attributes in identifying the risk of Mining Subsidence. Arch Min Sci 60(2):645-656 